\title{
Environmental Drivers of Fine-Scale Predator and Prey Spatial Dynamics in Sydney Harbour, Australia, and Adjacent Coastal Waters
}

\author{
Yuri Niella ${ }^{1}$ - Amy F. Smoothey ${ }^{2} \cdot$ Matthew D. Taylor $^{3,4} \cdot$ Victor M. Peddemors $^{2} \cdot$ Robert Harcourt $^{1}$
}

Received: 7 June 2021 / Revised: 13 October 2021 / Accepted: 25 October 2021 / Published online: 16 November 2021

(C) The Author(s) 2021

\begin{abstract}
Greater Sydney is the largest coastal city in Australia and is where bull sharks (Carcharhinus leucas) are present every summer and autumn. A decade of acoustic telemetry data was used to identify drivers of space use for bull sharks and their potential prey, according to standardised 6-h intervals using dynamic Brownian bridge movement models. Influences of environmental, physical, and biological variables on the areas of space use, location, and predator-prey co-occurrence were investigated with generalised additive mixed models. Rainfall in the catchment affected space use for all animals (i.e. teleost species and both sexes of sharks), with varying temporal responses. Male sharks responded most promptly to high rainfall moving upstream in $<1$ day, followed by teleosts ( 2 to 7 days), and female bull sharks after 4 days. Environmental luminosity affected male shark dispersal and space use, possibly indicating use of visual cues for foraging. Physical characteristics of habitat were important factors driving spatial overlaps between predator and prey in estuarine areas. In sandy embayments $<10-\mathrm{m}$ deep, males and female bull sharks overlapped with different species, whereas males and silver trevally (Pseudocaranx georgianus) co-occurred in deep holes $(>30 \mathrm{~m})$. Shark size influenced overlap between sexes, with smaller females less likely to co-occur with larger males $(\sim 50 \mathrm{~cm})$. Variability in space use suggests spatial segregation by sex and size in bull sharks, with individuals targeting similar prey, yet either in different areas or at different times, ultimately enabling them to exploit different resources when in the same habitats.
\end{abstract}

Keywords Acoustic telemetry · Bull sharks · Climate change $\cdot$ Movement patterns · Predator-prey interactions · Intraspecific interactions - Urbanisation - Refined shortest paths (RSP)

\section{Introduction}

A variety of abiotic cues underpin behavioural responses in animal movement; however, effectively determining their effects on habitat use is hindered by complex relationships

Communicated by Kevin M. Boswell

Yuri Niella

1 Department of Biological Sciences, Macquarie University, North Ryde, Sydney, NSW 2113, Australia

2 NSW Department of Primary Industries, Fisheries Research, Sydney Institute of Marine Science, Mosman, Sydney, NSW 2088, Australia

3 Department of Primary Industries, Port Stephens Fisheries Institute, Taylors Beach Road, Taylors Beach, NSW 2316, Australia

4 School of Biological, Earth and Environmental Science, University of New South Wales, Sydney, NSW 2052, Australia with biological factors (Schlaff et al. 2014). In South Africa's thicket biome, for instance, lions (Panthera leo) choose their kill sites based on higher vegetation density which might facilitate predator concealment and affect the ability of prey to escape from an attack (Davies et al. 2016). Prey abundance and distribution is an important factor influencing the movements of marine predators (Taylor et al. 2018a), with foraging success directly related to particular environmental conditions (Cherry and Barton 2017). For example, white sharks (Carcharodon carcharias) are seasonally present in False Bay, South Africa, to prey on Cape fur seals (Arctocephalus pusillus) and rely on low-light periods to increase attack success rate (Hammerschlag et al. 2006). The moon can affect predator occurrence in coastal waters indirectly through tide levels and behaviour of potential prey shoals and directly through visibility (Afonso et al. 2014; Wintner and Kerwath 2018; Niella et al. 2021a). Bull sharks (Carcharhinus leucas) are attracted to estuarine areas following heavy rainfall events, and this has been attributed 
to elevated biological productivity leading to an increase in prey abundance (Werry et al. 2018).

The large-scale movements of marine predators towards higher latitudes are often affected by seasonal changes in water temperatures (Block et al. 2011; Smoothey et al. 2016, 2019), but the extent to which this is related to physiological constraints on metabolism (Payne et al. 2018) or to seasonal presence of potential prey (Barnett et al. 2010) is yet to be fully understood. At smaller geographical scales, for example, within estuaries, animal movements are influenced by a complex interplay of factors such as tide (Walsh et al. 2013; Smoothey et al. 2019) and freshwater runoff and their associated effects such as salinity levels (Childs et al. 2008; Taylor et al. 2014). Heavy rainfall may override regular behavioural patterns of estuarine teleosts, with fish using deeper areas and becoming more active at night following periods of intense rain (Payne et al. 2013). In addition, fine-scale diel variability (i.e. over the circadian cycle of $24 \mathrm{~h}$ ) in movement is closely related to energy expenditure, facilitating biological processes such as foraging (Hammerschlag et al. 2006; Taylor et al. 2018a) and reproduction (Walsh et al. 2013; Gannon et al. 2015).

Intra-specific variation in animal movements is common in marine species (Speed et al. 2010; Hussey et al. 2015; Chin et al. 2016; Espinoza et al. 2021). In sharks, juveniles tend to move across smaller areas in comparison to adult conspecifics (Bansemer and Bennett 2011; Heupel et al. 2015; Lea et al. 2018; Lee et al. 2019), and in wide-ranging species, both sexes are capable of extensive dispersal associated with reproduction (Papastamatiou et al. 2013; Espinoza et al. 2016; Phillips et al. 2021), such as towards mating grounds or to give birth in the same nursery areas. Sympatric marine predators might reduce predation risk and avoid competition for resources by occupying different niches, including targeting different prey, occupying distinct areas or occurring in the same areas but at different times (Trystram et al. 2017; Heupel et al. 2019; Niella et al. 2021b; Riverón et al. 2021).

The bull shark is a euryhaline species capable of tolerating extreme salinity gradients (Pillans et al. 2008). While juveniles tend to remain within their natal estuaries (Werry et al. 2011), adults also make use of these ecosystems (Werry et al. 2018; Smoothey et al. 2019). Mature bull sharks can transit between freshwater and marine habitats within hours (McCord and Lamberth 2009) or remain in low salinity areas for days (Niella et al. 2017). While information at species level on diet composition of bull sharks is limited, studies in the Atlantic (Cottrant et al. 2021) and both eastern and western Pacific (Werry et al. 2011; Tillett et al. 2014; Estupiñán-Montaño et al. 2017; Espinoza et al. 2019) showed that teleost fish are an important component (i.e. $>83 \%$ contribution) of their diet. Along eastern Australia, bull sharks undertake seasonal migrations from the tropical Great Barrier Reef southward to temperate waters of Sydney during the summer (Smoothey et al. 2016, 2019; Lee et al. 2019; Espinoza et al. 2021). As oceans are gradually warming due to climate change, bull sharks are expected to spend more time at higher latitudes in future years, including the Sydney region (Niella et al. 2020b). Thus, there is a need to understand how predicted increases in the occurrence of bull shark for longer periods of time may influence ecosystem function.

This study uses acoustic telemetry to investigate finescale space use between bull sharks and five potential prey teleost species, tracked in estuarine and adjacent coastal waters off Sydney, over the decade 2009 to 2018. Identifying the environmental and biological (i.e. sex-specific differences and possible correlations with prey movements) drivers of space use and inter-group overlap will help reveal how intra-specific variation in predator movement patterns influences spatial segregation in highly urbanised coastal regions. It is predicted that (i) predators will target specific habitats (i.e. mangroves, rocky reefs) when influenced by environmental cues (e.g. tide and rainfall). Proximity to these habitats will increase prey encounter probability if putative prey moves closer to these habitats as these cues change (Sims et al. 2006; Gannon et al. 2015). (ii) Predator behaviour will differ between biological classes according to how resources are distributed in space and time (Ward et al. 2006); in particular, males and females will display divergent movement patterns and predator-prey relationships (e.g. targeting different species), due to different energetic demands between sexes (Austin et al. 2004) and to reduce intra-specific competition (Schlaff et al. 2020); and (iii) predator movement patterns will be influenced by environmental gradients due to the associated effects upon foraging success, or as a consequence of their prey responding to changes in such conditions (Jonsen et al. 2019).

\section{Materials and Methods}

\section{Study Area}

Sydney Harbour is a large, drowned river valley $30-\mathrm{km}$ long, covering an area of $55 \mathrm{~km}^{2}$ from four catchment basins (Fig. 1) with freshwater influence mostly from the Parramatta and Lane Cove Rivers (Roy et al. 2001). This is the busiest estuary in Australia with $90 \%$ of its coastal margin urbanised (Johnston et al. 2015) (Fig. S1). The entrance is $3-\mathrm{km}$ wide with a depth of $30 \mathrm{~m}$, and its complex topography is composed of deep holes up to 47-m deep and shallow embayments, with patches of mangrove and rocky reef habitats interspersed among modified areas (Fig. 1). 


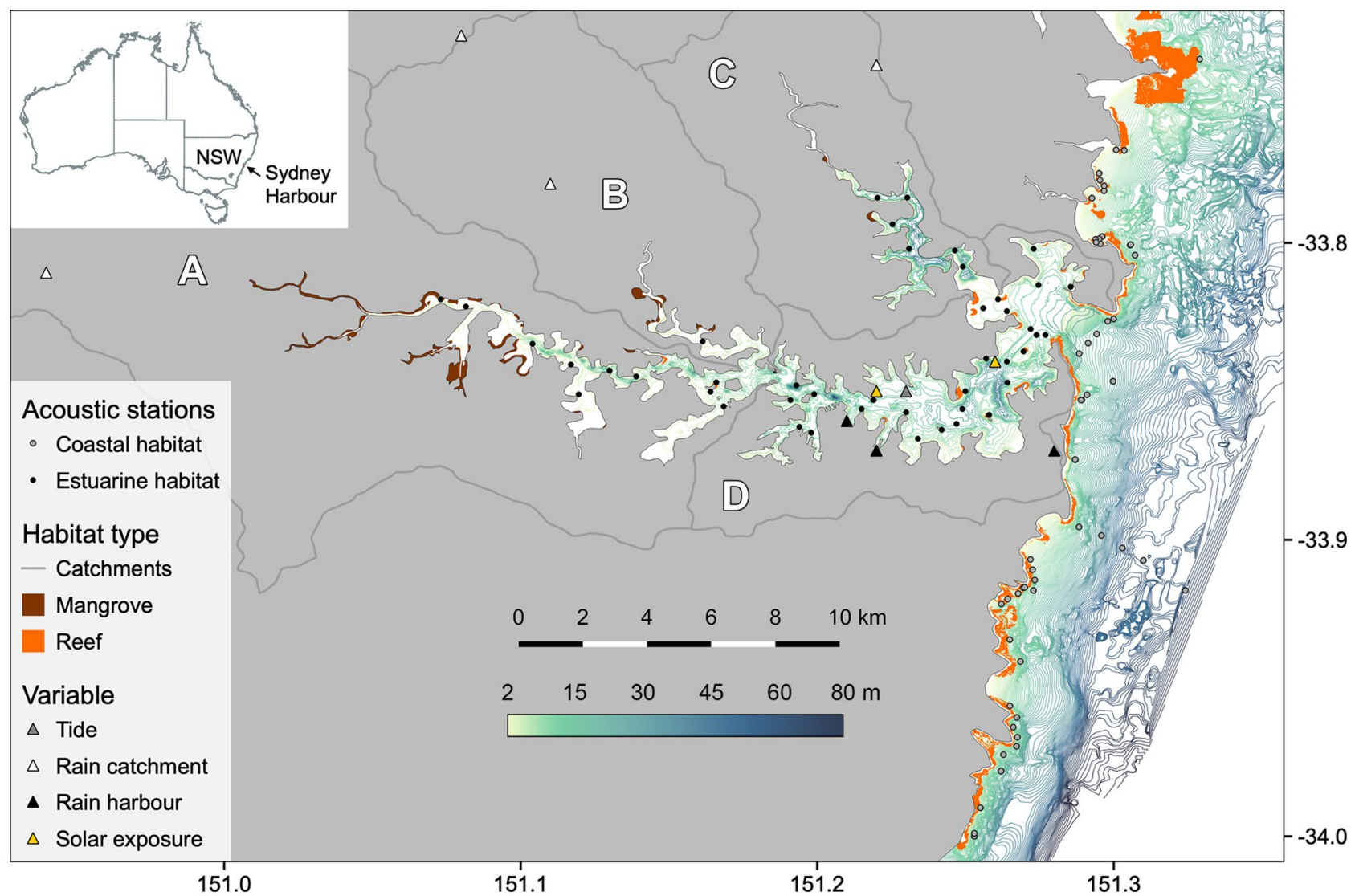

Fig. 1 Map of the study area comprising Sydney Harbour (estuarine habitat) and adjacent coastal waters (coastal habitat) off Sydney, Australia. Circles represent the deployment locations of acoustic stations. Contour lines depict fine-resolution bathymetry. The sampling loca-

\section{Acoustic Telemetry}

Between 2009 and 2018, adult and sub-adult bull sharks were caught using 200-m bottom set-lines consisting of 15 circle hooks (16/0) deployed with maximum soak times of around $2.5 \mathrm{~h}$ during summer and autumn months. Captured sharks were restrained alongside the research vessel and inverted to induce tonic immobility; total length was measured to the nearest centimetre and sex recorded. The teleost fish were caught using hook-and-line during trips guided by anglers experienced in the Sydney Harbour, during periods when capture was expected to be most successful. Teleost species included yellowfin bream (Acanthopagrus australis), yellowtail kingfish (Seriola lalandi), sea mullet (Mugil cephalus), silver trevally (Pseudocaranx georgianus), and mulloway (Argyrosomus japonicus). Sharks and teleosts were surgically implanted with acoustic transmitters (Innovasea V16 transmitters for sharks, expected battery life of 3,260 days; V9 and V13 transmitters for teleost fish, expected battery lives of 670 and 935 , respectively). Shark transmitters were programmed on a pseudo-random repeat tions of environmental data are also represented by triangles. Line boundaries delimit the catchments of (A) Parramatta River, (B) Lane Cove River, (C) Middle Harbour, and (D) Port Jackson

rate of $30-90 \mathrm{~s}$ or $40-80 \mathrm{~s}$, whereas fish transmitters pulses were set at 180-300-s intervals. Details on fishing and handling procedures can be found in Smoothey et al. (2016, 2019) and Taylor et al. (2018b).

A total of 177 tagged animals (Table S1) were monitored using an array of 105 acoustic receivers (Innovasea VR2W) deployed in Sydney Harbour and adjacent coastal waters, at depths ranging from 3 to approximately $80 \mathrm{~m}$ (Fig. 1). Data were downloaded every $6-12$ months and managed by New South Wales Department of Primary Industries Fisheries and the Integrated Marine Observing System Animal Tracking Facility.

\section{Standardised Analysis of Fish Fine-Scale Movements}

All analyses were performed in the software $\mathrm{R}$ (version 4.0.5; $\mathrm{R}$ core Team 2020). The raw acoustic data were initially filtered using the actel package (Flávio and Baktoft 2020) to identify and exclude any flawed detections, i.e. single daily detections or which constituted biologically impossible swimming speeds. The acoustic receivers were 
divided into two arrays, i.e. estuarine and coastal (Fig. 1), to account for differences between these habitat types. Here, we define estuarine as the region located $\geq 1 \mathrm{~km}$ upstream from the entrance of the estuary, whereas coastal was defined as directly from the entrance of the estuary to the surrounding northward and southward coastal regions (Fig. 1). Each array was analysed separately; however, since the effective detection range of acoustic receivers inside of Sydney Harbour was known to be $250 \mathrm{~m}$ (Smoothey et al. 2019), this same detection probability was considered for the coastal array.

Since bull sharks are seasonally present in Sydney waters (Smoothey et al. 2016, 2019), the movement patterns of the teleost fish were only analysed for the days when at least one bull shark was present in the study area. Dynamic Brownian bridge movement models (dBBMM) were calculated for each group of animals (Table S1) according to standardised timeframes with the RSP package (Niella et al. 2020a), in which the total monitoring period was divided into 6-h intervals, i.e. four daily timeframes $I=00: 00: 00-05: 59: 59, \mathrm{II}=06: 00: 00-11: 59: 59$; III $=12: 00: 00-17: 59: 59$; and IV $=18: 00: 00-23: 59: 59$. The total number of individuals detected in each timeframe for each group was collated, together with their areas of space use in squared metres for the $50 \%$ contours of the dBBMM, i.e. the areas where animals spent half of the tracking time during each timeframe. Since the study area habitat varies more considerably across longitude (Fig. 1), centroid longitude positions were calculated for each group including all estuarine 50\% contour dBBMM and considered representative of movement during the respective timeframes.

\section{Biological Variables}

Predator-prey co-occurrence was measured in both space and time during each daily timeframe. Using the 50\% dBBMM space use contours, the sizes of the overlapping areas between female and male bull sharks and each teleost species, as well as between the shark sexes, were calculated in pairs for each daily timeframe with RSP (Niella et al. 2020a).

To investigate for possible effects of shark size on the spatial overlaps between males and females, the average sizes of all male and female individuals detected in each timeframe were calculated. A derivative variable was then calculated to represent the standardised size differences between sex classes by subtracting the average male size from the average female size.

\section{Physical Variables}

To investigate the influence of habitat type on the co-occurrence between bull sharks and teleosts, the characteristics of the study area where the biological groups overlapped were used. For this purpose, the raster areas where the groups overlapped at the $50 \%$ contours of $\mathrm{dBBMM}$ were used to obtain the following information, in pairs and for each timeframe: (i) aspect, number of unique depth contour lines; (ii) maximum depth; (iii) area of mangrove habitat; and (iv) area of reef habitat (https://researchdata.edu.au/australian-coastal-waterwaysaggregated-product/817074, accessed on 5 February 2020). The areas of each habitat (i.e. mangrove and reef) directly correlated with the size of the overlapping areas, which meant that larger areas would directly implicate larger habitat values. Consequently, these two habitat variables were standardised by using the percentage of each habitat type in relation to the total size of the correspondent overlapping area.

\section{Environmental Variables}

While temperature is an important driver of ectotherm marine animal movements (Otway and Ellis 2011; DiGirolamo et al. 2012), water temperature measurements were not available across our study area with sufficient fine-scale resolution to be included in the analyses. Daily rainfall and solar exposure data were obtained from the Australian Bureau of Meteorology (http://www.bom.gov.au/climate/ data/, accessed on 3 July 2020) for nine stations located in the study region (Fig. 1). While many studies have included the amount of daily rainfall in their analyses, here, we tested this component with both spatial and temporal gradients. First, since this is a large area (i.e. $\sim 640 \mathrm{~km}^{2}$ ), we hypothesise that rainfall at the catchment (Rain catchment, Fig. 1) will have a more pronounced effect upon this system, e.g. through leaching and nutrient transport, than rainfall directly upon the main river channel (i.e. Port Jackson catchment; Rain harbour, Fig. 1). Secondly, not only the amount of rain in the catchments would be important, but these should be considered according to temporal intervals, which could then allow this hydrological cycle to influence the fish movements. Therefore, rainfall was considered as two independent variables: (i) rain harbour, daily means between three stations located at the Port Jackson catchment; and (ii) rain catchment, daily means between four stations located at the Parramatta, Lane Cove, and Middle Harbour catchments (Fig. 1). To investigate for possible intervals between rainfall in the catchment and fish movements, this variable was tested with temporal lags ranging from 0 (i.e. on same day) up to 8 days, as this interval has previously been identified to influence bull shark movements towards estuarine areas following high rainfall events (Werry et al. 2018).

The amount of light that reaches the surface of the Earth from any astronomical object increases proportionally to its angle in the sky (Austin et al. 1976). To calculate a finescale index of environmental luminosity, solar exposure data were considered for day-time periods, while moonlight was used for night-time. Solar exposure daily values were 
considered as the mean between the two meteorological stations (Fig. 1), whereas daily moonlight values were obtained using the lunar package (Lazaridis 2014) as the percentage of the moon illuminated by the sun, i.e. continuous ranging from new (0) to full moon (1). Following Niella et al. (2021b), hourly values of environmental luminosity combined from both daily solar exposure and moonlight variables were weighted by the respective maximum angles of the sun and the moon in the sky (Appendix 1). Mean environmental luminosity values during the corresponding timeframes with acoustic data were then used in the analyses.

Hourly tide heights were obtained for a location inside Sydney Harbour (Fig. 1) using XTide (https://flaterco.com/ xtide/, accessed on 13 July 2020). To account for both height and direction of tide representative of each timeframe, a derivative value was calculated by subtracting the maximum tide height in the timeframe of interest by the maximum tide height during the previous timeframe. This standardisation resulted in a derivative tide height variable ranging from negative (i.e. ebbing tide periods) to positive (i.e. rising tide periods) values and their respective numeric amplitudes (Appendix 1).

\section{Analytical Approach}

Patterns of space use were analysed using three metrics of animal movement as the response variables: (i) the size of the $50 \% \mathrm{dBBMM}$ areas (in $\mathrm{m}^{2}$ ), the areas where each group of animals spent half of their tracking times; (ii) the longitude centroid locations, to investigate fish movements along the estuary since it runs primarily from east to west; and (iii) the size of the overlapping dBBMM areas (in $\mathrm{m}^{2}$ ) at the $50 \%$ level, overlaps in space and time in pairs between each bull shark sex and the teleost species. Generalised additive mixed models (GAMMs) were run using the mgcv package (Wood 2017) for each of the three response variables using Gamma families of error distribution. Models were fitted separately for coastal and estuarine habitats including the variables sampling day and year as random effects to account for the sampling units. To account for the number of individuals tracked possibly influencing the response variables, the logarithm of total individuals detected per timeframe was included in the models as an offset covariate, i.e. the number of individuals from each group in the group-specific and longitude centroid models, and the sums between the respective number of predator and prey individuals tracked in the overlap models. Multicollinearity was assessed between continuous variables with Pearson's correlations and the degrees of the smoothing functions kept at five (independent effects) and 15 (interacting effects) to avoid model overfitting. Variables were gradually added to a previous simpler nested model based on lower Akaike information criterion (AIC) values and selected after a significant analysis of variance (ANOVA) indicated the new model to be significantly different. Final models were selected based on higher AIC weights (Appendix 1) and visually inspected for normal residual distributions.

\section{Modelling Group-Specific Patterns of Space Use}

The candidate predictor variables included (i) rain at the catchment, 0 to 8-day lag as individual effects; (ii) rain in the harbour; (iii) derivative tide; and (iv) the interaction between mean environmental luminosity and circadian period, timeframe $\mathrm{I}=$ late night, timeframe $\mathrm{II}=$ morning, timeframe III $=$ afternoon, and timeframe IV = early night. The variable circadian period controls for the diel cycle between day versus night-time periods in number of hours, and is exclusively temporal, while the variable environmental luminosity is strongly influenced by fine-scale factors and equates to the approximate amount of light reaching the water surface hourly from the sun (weighted by cloud cover) or the moon (weighted by moon phase) in each of these two periods (Appendix 1). The total GAMM formula used for the group-specific models (i.e. including 50\% dBBMM area or longitude centroid location as the response variables) corresponded to:

$$
\begin{aligned}
& \text { Response } \sim \text { Raincatchment }_{1 \text { day }}+\cdots+\text { Raincatchment }_{8 \text { days }} \\
& \quad+\text { Rainharbour }+ \text { Derivativetide }+(\text { Environmentalluminosity } \\
& \left.\quad \times \text { Circadianperiod })+(1 \mid \text { Samplingday })+(1 \mid \text { Year })+\text { offset }_{=} \log _{10} \text { (numberofindividuals }\right)
\end{aligned}
$$

\section{Modelling Inter-group Co-occurrence}

In addition to the environmental predictors, physical variables were also tested to assess their possible influence upon the sizes of the $50 \%$ dBBMM overlapping areas between predators and prey. These included an interaction between aspect and maximum depth and the corresponding percentage areas of mangrove and reef habitat types. The total GAMM formula used for the overlapping models was:

$$
\begin{aligned}
& \text { Response } \sim \text { Raincatchment }_{1 \text { day }}+\cdots+\text { Raincatchment }_{8 \text { days }} \\
& + \text { Rainharbour }+ \text { Derivativetide }+ \text { Mangrovearea }+ \text { Reefarea } \\
& +(\text { Environmentalluminosity } \times \text { Circadianperiod }) \\
& +(\text { Aspect } \times \text { Maximumdepth })+(1 \mid \text { Samplingday })+(1 \mid \text { Year }) \\
& + \text { offset }=\log _{10}(\text { number of sharks }+ \text { number of teleosts })
\end{aligned}
$$


A 2010

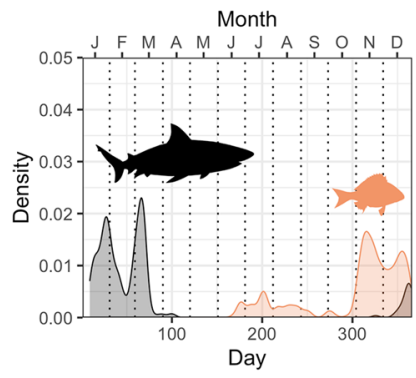

2015

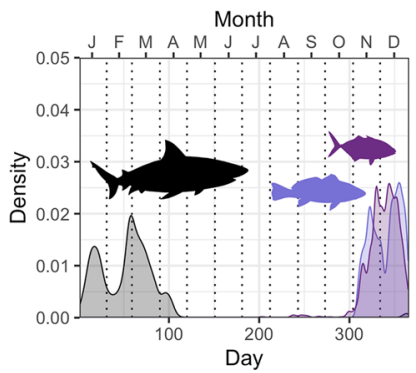

2011

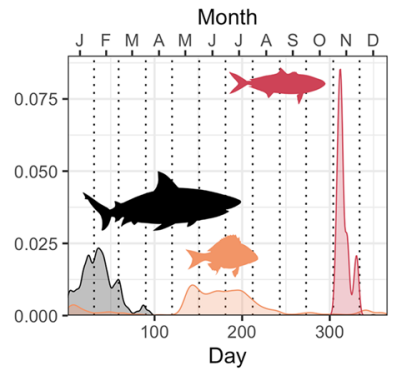

2016

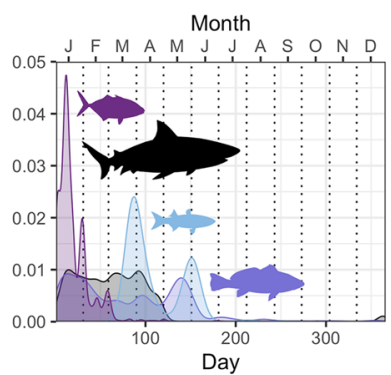

2012

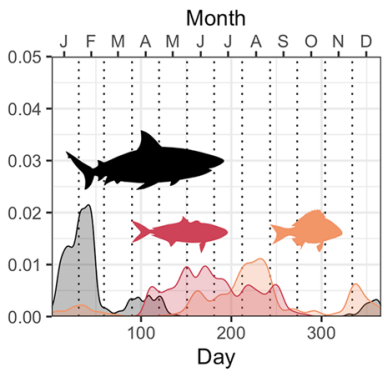

2017

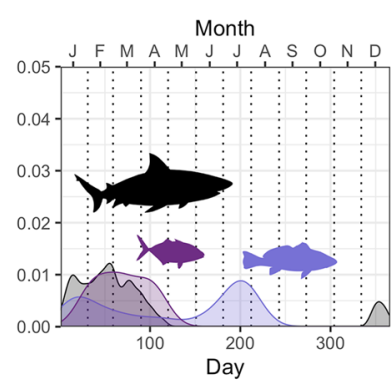

2013

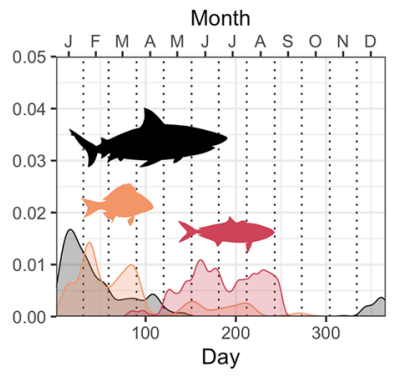

B

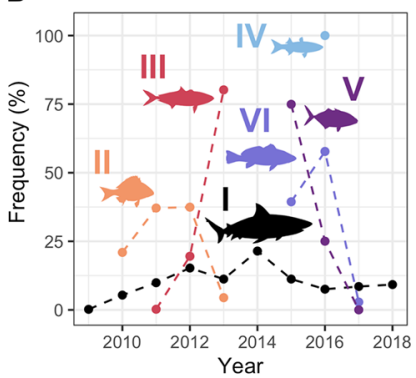

Fig. 2 Frequency distributions of total acoustic detections by (a) day/ month and (b) year for each of the fish species tracked ( $I=$ bull shark, $\mathrm{II}=$ yellowfin bream, III = yellowtail kingfish, IV = sea mullet, V= sil-

\section{Results}

\section{Overall Patterns of Detection}

Bull sharks were continuously monitored in the study region between 2009 and 2018, while teleosts were tracked between 2010 and 2013 (yellowfin bream and yellowtail kingfish) and between 2015 and 2017 (sea mullet, silver trevally, and mulloway) (Fig. 2). Although sea mullet were only detected in 2016, the remaining teleosts were tracked simultaneously with bull sharks for three to four consecutive years (Fig. 2). Detections of most teleost species peaked with the seasonal presence of bull sharks from November to May, yet yellowtail kingfish were detected more between ver trevally, and VI=mulloway) in Sydney Harbour. Please note individual panels are missing for 2009, 2014, and 2018 (A) as only bull sharks were tracked in these years (B)

May and September (Fig. 2). Yellowtail kingfish had the greatest number of detections across the study region (combined estuarine and coastal areas; Fig. S2a), yellowfin bream were detected for longer periods of time (Fig. S2b), and bull sharks were detected across a greater number of stations than any teleost species (Fig. S2c).

\section{Group-Specific Patterns of Space Use}

\section{Size of Space Use Areas}

No significant patterns were found for sea mullet due to limited detections (Fig. S2). Variation in size of 50\% contours $\mathrm{dBBMM}$ in coastal habitats was only significant for
Table 1 Generalised additive mixed models of area size variation at the $50 \%$ dynamic Brownian bridge movement model contours in the corresponding significant habitats, including the effective degrees of freedom (edf), reference degrees of freedom (Ref.df), $F$-values $(F)$, and $p$-values $(p)$

\begin{tabular}{llllrrr}
\hline Group & Habitat & Variable & edf & Ref.df & \multicolumn{1}{c}{$F$} & $p$ \\
\hline Female shark & Coastal & Rain catchment 4 days & 1.21 & 1.40 & 8.26 & 0.004 \\
& Estuarine & Rain catchment 4 days & 3.85 & 3.98 & 10.63 & $<0.001$ \\
Male shark & Coastal & Rain catchment 4 days & 3.82 & 3.98 & 7.21 & $<0.001$ \\
& Estuarine & Rain catchment 2 days & 3.82 & 3.98 & 9.27 & $<0.001$ \\
& & Circadian period Xenvi- & 12.64 & 13.73 & 2.44 & $<0.001$ \\
& & ronmental luminosity & & & & \\
Yellowfin bream & Estuarine & Rain catchment 4 days & 3.92 & 3.99 & 16.56 & $<0.001$ \\
& & Derivative tide height & 2.81 & 3.31 & 3.72 & 0.007 \\
Yellowtail kingfish & Estuarine & Rain catchment 6 days & 1.94 & 2.13 & 3.35 & 0.042 \\
Mulloway & Estuarine & Rain catchment 7 days & 1.31 & 1.54 & 19.31 & $<0.001$ \\
\hline
\end{tabular}




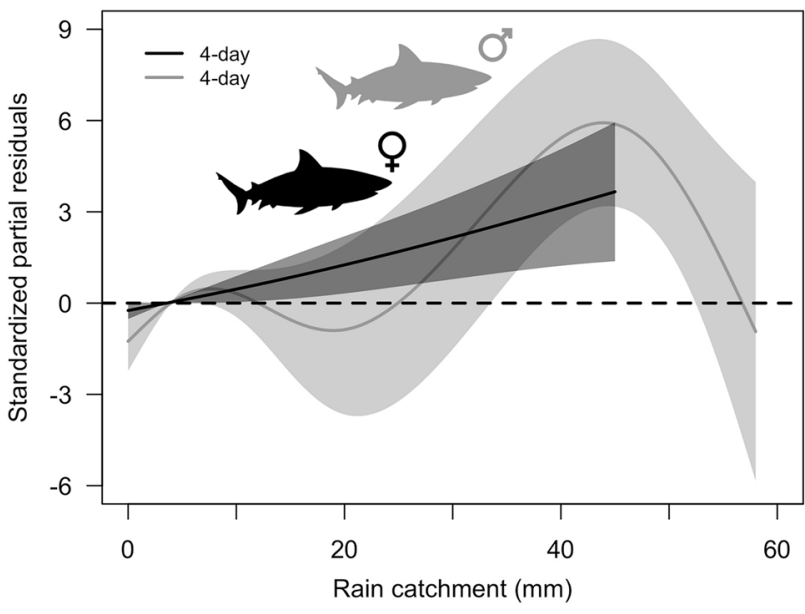

Fig. 3 Generalised additive mixed model of variation in size of area used at the 50\% level dynamic Brownian bridge movement models in coastal habitat for male and female bull sharks, including the significant effects of rainfall at the catchment with 4-day lags. Shaded areas and dashed line represent $95 \%$ confidence intervals and null effects, respectively

male and female bull sharks and influenced by rainfall in the catchments with temporal lags of 4 days (Table 1). Bull sharks spent half of their monitored time in larger coastal areas associated with 4 days after higher rainfall levels in the catchments, and males exhibited a slightly greater response than females (Fig. 3). Rainfall in the catchment influenced estuarine habitat usage for all fish groups with behavioural responses correlated with different temporal lags (Table 1). All groups spent more time (i.e. 50\% level of dBBMM) in larger estuarine areas associated with higher rainfall levels, but male bull sharks responded more rapidly (i.e. 2-day lag) and exhibited the greatest space use amplitudes (Fig. 4a).
The derived tide height and interaction of environmental luminosity with circadian period also influenced space use areas in estuarine habitats for yellowfin bream and male bull sharks, respectively (Table 1). Bream used larger areas at either ebbing (negative) or rising (positive) tides with higher amplitudes (Fig. 4b). Male bull sharks spent more time and used larger estuarine areas during afternoon periods (12:00:00-17:59:59) with higher environmental luminosity and conversely also during darker early nights (Fig. 4c).

\section{Estuarine Movements}

Rainfall in the catchment was the most important variable influencing the variation in longitude centroid locations for most of the fish groups, but species-specific temporal lags were observed (Table 2). Male and female bull sharks responded to temporal lags of 0 and 7 days, respectively, and showed opposite trends according to intermediate rainfall levels up to $70 \mathrm{~mm}$, with females tending to remain downstream and males dispersing further upstream (Fig. 5a). Yellowfin bream showed a clear bimodal pattern in relation to rainfall in the catchment after 2 days, with these fish remaining downstream when rainfall was $<35 \mathrm{~mm}$ and moving further upstream with increased rain levels (Fig. 5a). Mulloway were influenced by heavier catchment rainfall following a lag of six days, and they tended to move further upstream than the other species (Fig. 5a).

Derived tide height and interacting environmental luminosity with circadian period were also responsible for estuarine movements of female and male sharks (Table 2). Female bull sharks remained downstream during both
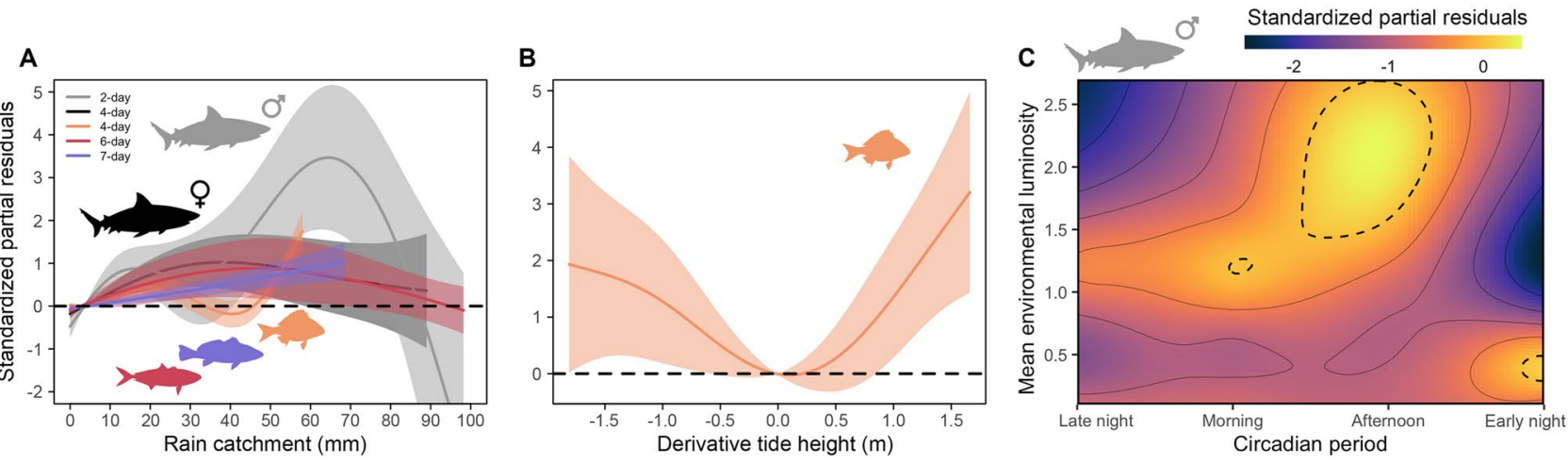

Fig. 4 Generalised additive mixed models of variation in size of area used at the $50 \%$ level dynamic Brownian bridge movement models in estuarine habitat for male and female bull sharks, yellowfin bream, mulloway and kingfish, including the corresponding significant effects of (a) rainfall at the catchment with respective temporal lags per group, (b) derivative tide height, and (c) interactive effect between environmental luminosity and circadian period. Shaded areas and dashed lines represent $95 \%$ confidence intervals and null effects, respectively 
Table 2 Generalised additive mixed models of longitude centroid variation at the $50 \%$ level dynamic Brownian bridge movement models in estuarine habitat, including the effective degrees of freedom (edf), reference degrees of freedom (Ref.df), $F$-values (F), and $p$-values (p)

\begin{tabular}{|c|c|c|c|c|c|}
\hline Group & Variable & edf & Ref.df & $F$ & $p$ \\
\hline \multirow[t]{2}{*}{ Female shark } & $\begin{array}{l}\text { Derivative tide } \\
\text { height }\end{array}$ & 2.69 & 3.22 & 6.27 & $<0.001$ \\
\hline & $\begin{array}{l}\text { Rain catchment } \\
7 \text { days }\end{array}$ & 3.09 & 3.52 & 4.40 & 0.003 \\
\hline \multirow[t]{2}{*}{ Male shark } & $\begin{array}{l}\text { Circadian } \\
\text { period } \times \text { environ- } \\
\text { mental luminos- } \\
\text { ity }\end{array}$ & 8.13 & 8.84 & 6.46 & $<0.001$ \\
\hline & $\begin{array}{l}\text { Rain catchment } \\
0 \text { days }\end{array}$ & 2.53 & 3.04 & 8.16 & $<0.001$ \\
\hline Yellowfin bream & $\begin{array}{l}\text { Rain catchment } \\
2 \text { days }\end{array}$ & 3.72 & 3.95 & 4.45 & 0.002 \\
\hline Mulloway & $\begin{array}{l}\text { Rain catchment } \\
6 \text { days }\end{array}$ & 1.43 & 1.73 & 10.35 & $<0.001$ \\
\hline
\end{tabular}

ebbing and rising tides (Fig. 5b). During periods of higher environmental luminosity, male bull sharks dispersed further upstream during the day and moved downstream late at night, showing the opposite trend during periods of lower environmental luminosity (Fig. 5c).

\section{Co-occurrence Patterns in Space and Time}

\section{Co-occurrence Between Bull Sharks and Teleost}

Physical variables were most influential on bull shark and teleost co-occurrence in estuarine habitats (Table 3). Spatial overlap of yellowfin bream and female bull sharks occurred mostly in complex and shallow areas (Fig. 6a), whereas male bull sharks occurred more prominently in areas with lower reef coverage (Fig. 6b), 3 days after higher rainfall in the catchment (Fig. 6c). Male bull sharks and mulloway overlapped in both space and time, mostly in more structurally complex and shallow areas (Fig. 6d); however, the
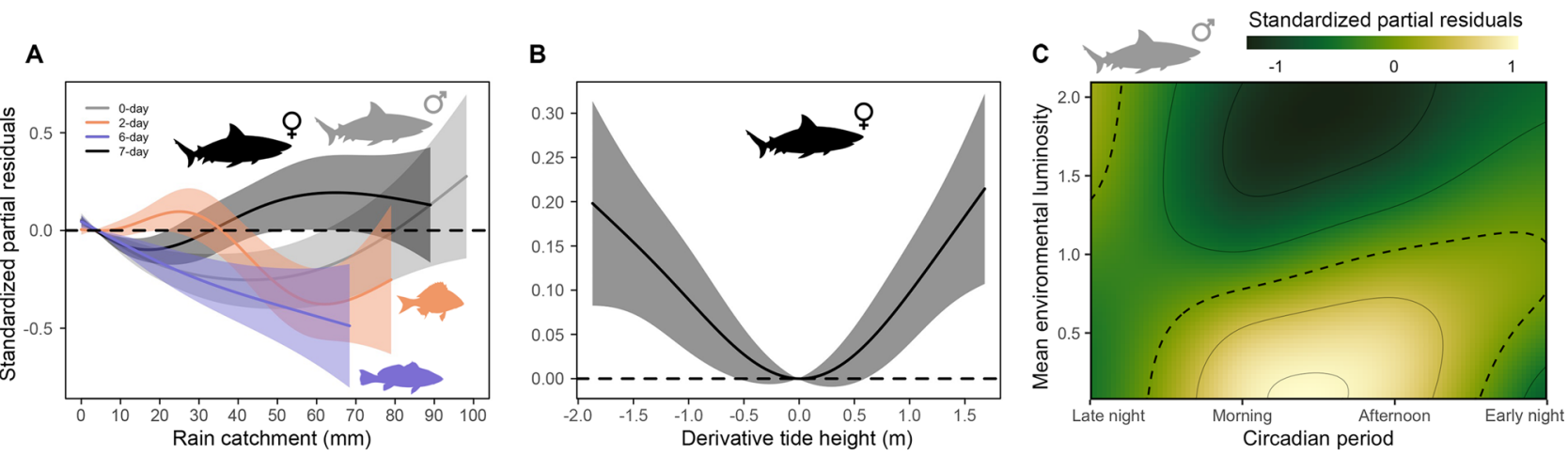

Fig. 5 Generalised additive mixed models of longitude centroid variation (high values $=$ downstream movement) at the $50 \%$ level dynamic Brownian bridge movement models in estuarine habitat for male and female bull sharks, yellowfin bream and mulloway, including the corresponding significant effects of (a) rainfall at the catchment with respective temporal lags per group, (b) derivative tide height, and (c) interactive effect between environmental luminosity and circadian period. Shaded areas and dashed lines represent $95 \%$ confidence intervals and null effects, respectively
Table 3 Generalised additive mixed models for variation in area overlap at the 50\% level dynamic Brownian bridge movement models in estuarine habitat between shark and teleost groups, including the effective degrees of freedom (edf), reference degrees of freedom (Ref. df), $F$-values $(F)$, and $p$-values $(p)$

\begin{tabular}{lllrrr}
\hline Shark & Teleost & Variable & edf & Ref.df & $F$ \\
\hline Female & Yellowfin bream & Aspect $\times$ maximum depth & 12.38 & 13.55 & 126.60 \\
Male & Yellowfin bream & Reef frequency & 3.77 & 3.98 & 9.76 \\
& & Rain catchment 3 days & 3.92 & 3.99 & 5.76 \\
Male & Silver trevally & Aspect $\times$ maximum depth & 13.74 & 13.99 & 119.10 \\
Male & Mulloway & Aspect $\times$ maximum depth & 11.95 & 13.38 & 40.001 \\
\hline
\end{tabular}



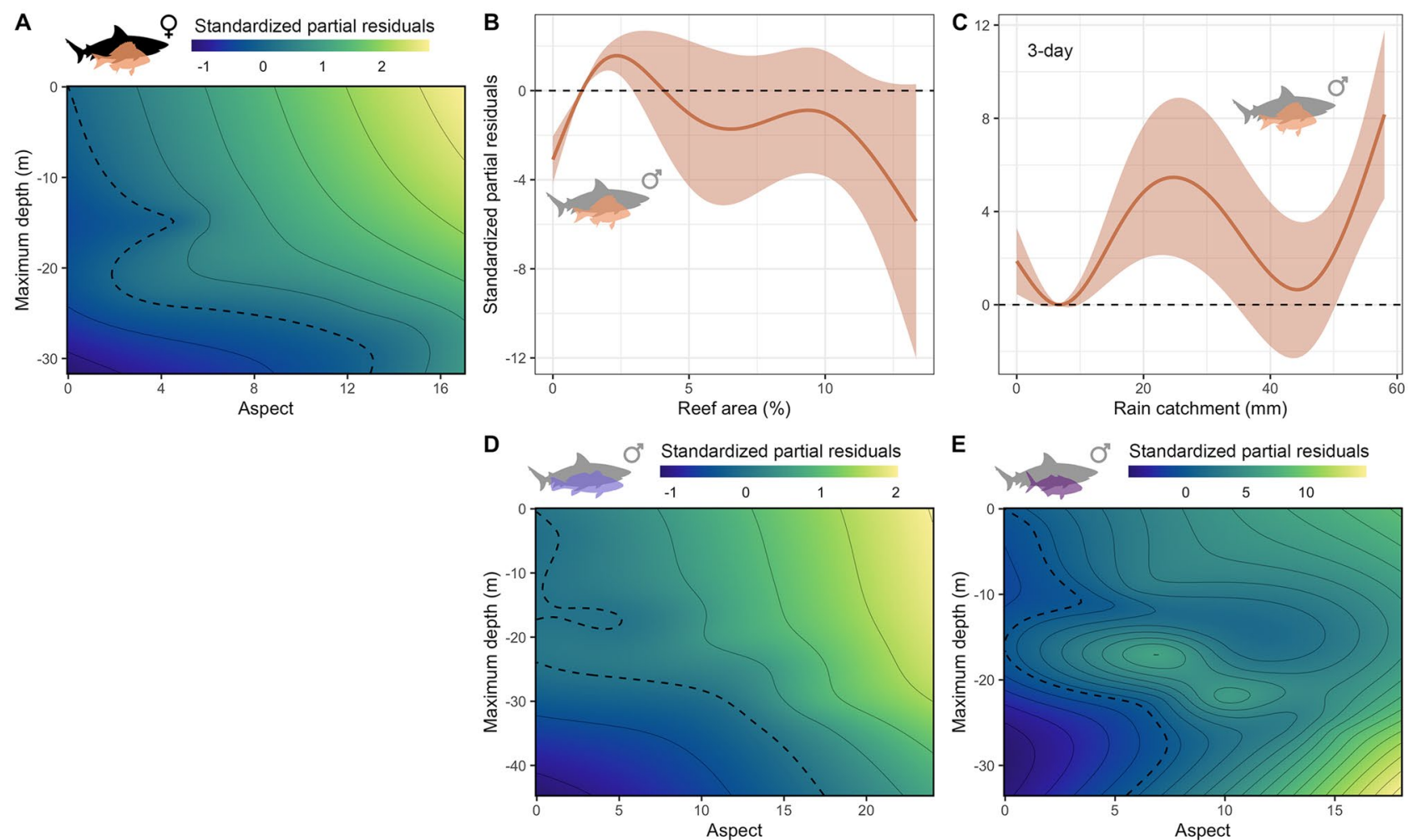

Fig. 6 Generalised additive mixed models of area overlap variation at the 50\% level dynamic Brownian Bridge Movement Models in estuarine habitat between (a) female sharks and yellowfin bream, (b-c) male sharks and yellowfin bream, (d) male sharks and mulloway, and (e) male sharks and silver trevally, including the significant effects of

co-occurrence of silver trevally with male sharks showed a bimodal response at depths between 10 and $20 \mathrm{~m}$ with lower complexity and peaked at depths $>20 \mathrm{~m}$ in areas with more structurally complex habitats (Fig. 6e).

\section{Co-occurrence Between Female and Male Sharks}

In both coastal and estuarine areas, habitat complexity had the greatest influence on female and male shark cooccurrence, followed by catchment rainfall with 4-day lags;

Table 4 Generalised additive mixed models of area overlap variation between female and male bull sharks for the $50 \%$ level dynamic Brownian bridge movement models in the corresponding significant habitats, including the effective degrees of freedom (edf), reference degrees of freedom (Ref.df), $F$-values $(F)$, and $p$-values $(p)$

\begin{tabular}{llrrrl}
\hline Habitat & Variable & edf & Ref.df & $F$ & \multicolumn{1}{l}{$p$} \\
\hline Coastal & Aspect $\times$ maximum depth & 9.97 & 11.98 & 31.38 & $<0.001$ \\
& Rain catchment 4 days & 3.79 & 3.97 & 11.65 & $<0.001$ \\
Estuarine & Aspect $\times$ maximum depth & 10.76 & 12.58 & 56.69 & $<0.001$ \\
& Rain catchment 4 days & 2.84 & 3.28 & 6.01 & $<0.001$ \\
& Size difference & 1.00 & 1.01 & 8.09 & 0.004 \\
\hline
\end{tabular}

(a, d, e) interactive effect between maximum depth and aspect, (b) percentage of reef habitat cover, and (c) rainfall at the catchment with 3-day lag. Shaded areas and dashed lines represent 95\% confidence intervals and null effects, respectively

however, male-female size difference was only significant for estuarine overlap (Table 4). This sex class overlap occurred mostly in $>40 \mathrm{~m}$ and complex coastal habitats, with shark co-occurrence in estuarine habitats exhibiting a bimodal response in relation to complex habitats, either in areas $<10 \mathrm{~m}$ or between 20 and 30-m deep (Fig. 7a). Bull shark overlap increased in coastal areas with rainfall levels $>35 \mathrm{~mm}$, and peak co-occurrence in estuarine habitat was observed in association with $\sim 50 \mathrm{~mm}$ of rain in the catchment (Fig. 7b). There was greater overlap inside the estuary when females were $\sim 50 \mathrm{~cm}$ larger than males and lower co-occurrence between smaller females and larger males (Fig. 7c).

\section{Discussion}

While many studies have identified linkages between animal movements and particular abiotic conditions, it is likely that concomitant changes in additional drivers such as predator avoidance or prey availability contribute to the patterns observed (Schlaff et al. 2014). By using a standardised method to analyse movements according to fixed temporal 

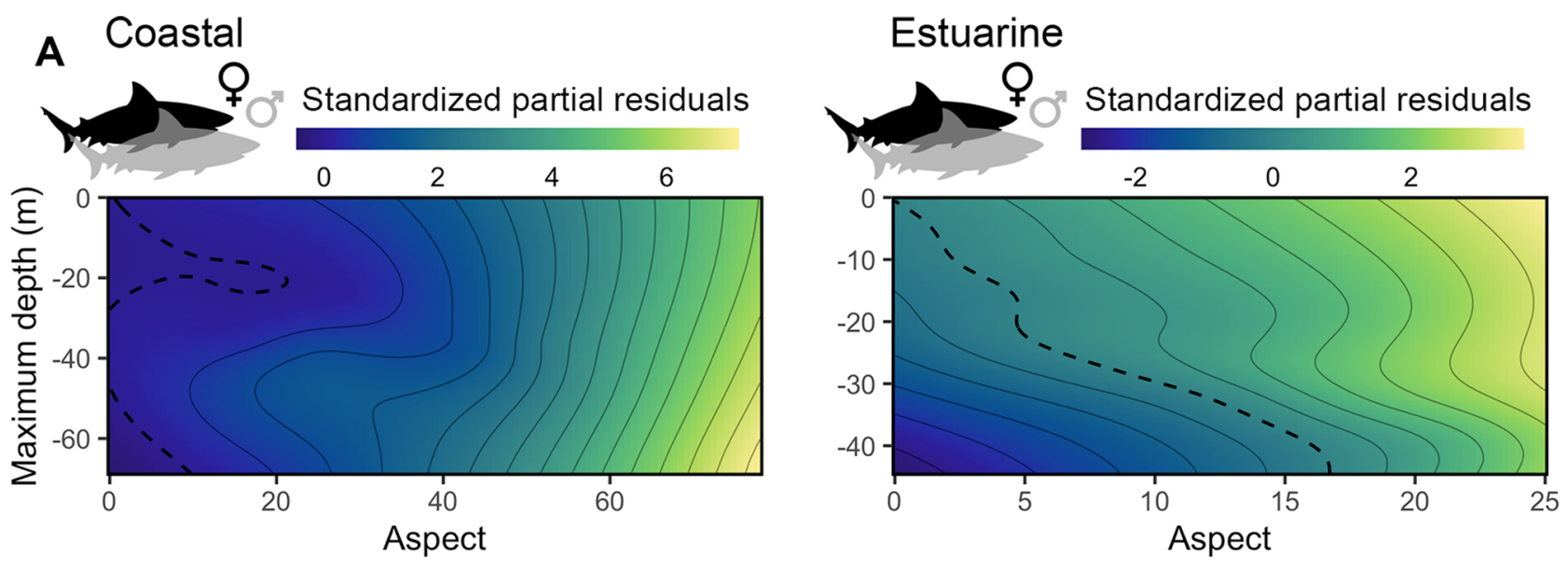

\section{B}
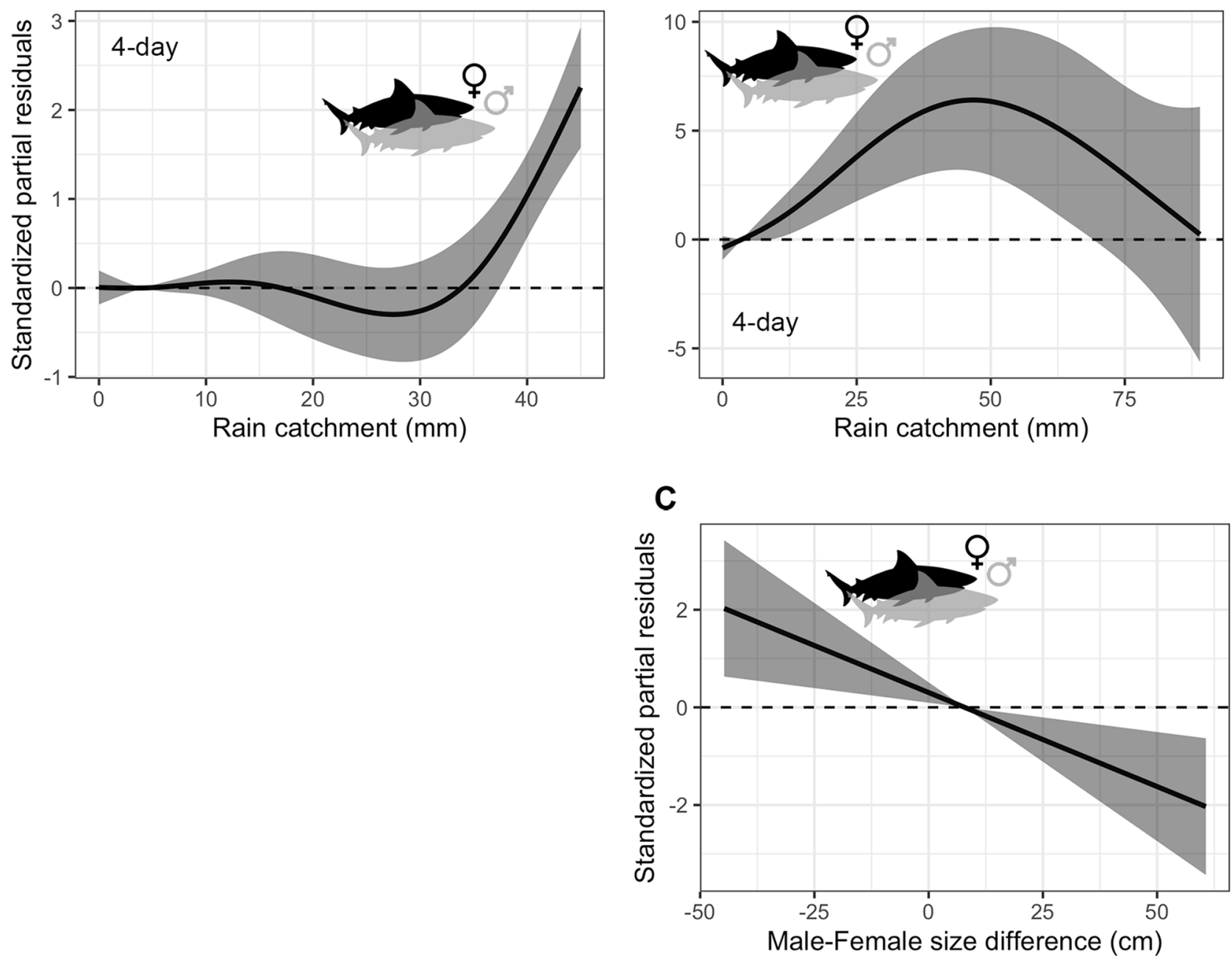

Fig. 7 Generalised additive mixed models of area overlap variation between female and male bull sharks at the 50\% level dynamic Brownian bridge movement models in the corresponding significant habitats, including the corresponding significant effects of (a) inter-

active effect between maximum depth and aspect, (b) rainfall at the catchment with 4-day lag, and (c) difference between average male and female shark size. Shaded areas and dashed lines represent $95 \%$ confidence intervals and null effects, respectively 
windows (Niella et al. 2020a), we were able to reveal finescale patterns of predator and prey space use and identify the drivers that subsequently enhance an understanding of ecosystem dynamics in a highly urbanised coastal region. Yellowtail kingfish are a high-profile recreational fisher target species in Sydney Harbour, yet the lack of significant cooccurrence between bull sharks and yellowtail kingfish indicates that this teleost species is unlikely to be an important food source for bull sharks as they exhibit different seasonal occurrences at the latitude of our study site. Conceptual models that describe spatial segregation in elasmobranch species are evolving rapidly. In tropical Australian estuaries, differences in nursery habitat use between juvenile bull and speartooth (Glyphis glyphys) sharks have been related to distinct diets, leading to the two species occupying separate core areas within the same estuary (Dwyer et al. 2020). While differences in space use of sympatric predators are often attributed to competition (Niella et al. 2021b), little is known about how individuals from the same species might coexist. Our approach accounted for intra-specific variation (i.e. between sex classes) in bull sharks, revealing that each group responded to particular environmental gradients.

Rainfall influences fish dynamics and productivity in estuarine areas by affecting spawning success, dispersal of eggs and larvae, early-life survival, migration, food supply, and water quality (Robins et al. 2005; Meynecke et al. 2006; Hoguane et al. 2012). By including rainfall as two independent variables in our analyses (catchment basins versus directly in Sydney Harbour), we identified that fine-scale movements of fish were more closely associated with rainfall in the catchments, with group-specific lagged responses. All groups that responded to rainfall made use of larger areas, as a consequence of higher rainfall in the river catchments. These findings support earlier studies showing that salinity and turbidity fluctuations arising from rainfall are responsible for influencing teleost (Payne et al. 2013; Taylor et al. 2014) and shark (Werry et al. 2011; Schlaff et al. 2014) movements in estuarine habitats. During intermediate $(\sim 30 \mathrm{~mm})$ and stronger $(>50 \mathrm{~mm})$ rainfall levels, the yellowfin bream became more active and moved further upstream, while overlapping more with male bull sharks. Sharks detect and respond (e.g. flight behaviour) to major changes in environmental parameters, such as those observed during tropical storms and hurricanes, even at very early ages (Udyawer et al. 2013; Strickland et al. 2020). Werry et al. (2018) suggested that bull sharks are attracted to estuarine areas following high rainfall events due to increased prey availability. Here, we reveal that their behaviour is more complex than previously reported, with males responding to high rainfall events more rapidly (within 0 to 4 days) than females (within 4 to 7 days), suggesting that they responded to different cues, or to different gradations of possible cues such as salinity or water opacity.
Changes in prey capture kinematics when deprived of visual cues have been observed in species with both pelagic and benthic feeding strategies (Gardiner et al. 2017), suggesting that vision is an important sense for some sharks when foraging (Hueter et al. 2004). In Sydney Harbour, environmental luminosity influenced movement patterns of male bull sharks, which moved upstream and used larger areas on days with higher luminosity (i.e. lower cloud cover). During the day, bull sharks make use of areas with steep drop-offs (Smoothey et al. 2019), where they were found to overlap with silver trevally. While this implies that male bull sharks may use sunlight to detect prey at deeper depths during the day, it is also possible that they could be simply seeking cooler temperatures or quieter areas during warmer days. Male sharks were found to spend most of their time across larger areas during darker early nights, suggesting a shift towards becoming more active during these low-light periods when it might be more difficult for their prey to detect them (Martin and Hammerschlag 2012).

Growing evidence points to spatial segregation among sympatric predator species (Waite et al. 2012; Niella et al. 2021b; Riverón et al. 2021); however, little is yet known about intra-specific trends in estuarine habitats. Intra-specific variation in habitat use in the marine environment is frequently attributed to one group of individuals having narrower home ranges than the other within the same region (Field et al. 2005; Chin et al. 2016; Lea et al. 2018; Schlaff et al. 2020) and/or to partial migrations, in which only part of a population is found to move towards different areas driven by an interplay between seasonality in water temperatures and foraging and reproduction cues (Papastamatiou et al. 2013; Espinoza et al. 2021). Male bull sharks are more common in Sydney Harbour than females (Smoothey et al. 2019), and co-occurrence inside the estuary was higher when females were larger than males. Sydney Harbour is unlikely to be a mating site (Smoothey et al. 2016), and we propose that, in the harbour, smaller females may avoid sharing foraging grounds with larger males to reduce competition for resources. According to this size segregation, smaller males would be expected to avoid larger females; however, this trend could not be found in our study likely due to the low presence of large female bull sharks in Sydney waters. We also found evidence that adult bull sharks may target different teleost prey in shallow sandy embayments, since female and male sharks significantly overlapped with different teleost species in these habitats. Female sharks tended to remain downstream during changing tide periods, coinciding with times when yellowfin bream used larger areas. Male bull sharks overlap with yellowfin bream when they moved upstream on the days with heavier rain in the catchments, 1 day before the bream moved across larger areas up the river (i.e. 3 days after higher rainfall). This suggests that male sharks may anticipate changes in prey behaviour, which 
could help reduce competition with females for the same resource. Since teleost fish are an important food resource for bull sharks (Tillett et al. 2014; Estupiñán-Montaño et al. 2017; Espinoza et al. 2019; Cottrant et al. 2021), the overlaps observed between sharks and teleost may, at least in part, be related to predator-prey relationships. However, we caution that patterns exhibited here remain hypothetical, since we could not confirm that these teleost species were targeted by bull sharks. Similarly, we cannot confirm differences in male and female diet due to the lack of stable isotope or stomach content data from this region.

Noise derived from anthropogenic activities affects a variety of aquatic animals; however, most studies have focused on marine mammals (Duarte et al. 2021). Previous research has indicated that human-induced noise impacts fish through reductions in movement patterns, feeding success, and slower flight from predators (Payne et al. 2014; Leduc et al. 2021). Anthropogenic noise also influences elasmobranch behaviour, with sharks increasing time spent swimming and avoiding noisier areas when anthropogenic noise levels exceeded biological noise levels in an aquarium (de Vincenzi et al. 2021). Throughout Sydney Harbour, there is substantially more boat traffic during day-light hours. Smoothey et al. (2019) record bull sharks occupying deeper water during the day, potentially indicating that they, too, may avoid areas with higher human-induced noise. Additional support for potential avoidance of noise may be attributed to male bull shark movement upstream on days of increased sunlight, when there is increased boating activity in Sydney Harbour, especially in the main harbour area located within the Port Jackson catchment (Fig. 1) (Widmer and Underwood 2004). Although these findings suggest there are potentially adverse anthropogenic influences on bull sharks in urbanised estuaries, their continuing use of this habitat (Smoothey et al. 2019) suggests they are resilient to coexisting with humans. Bull sharks migrate southwards along the east coast of Australia during the austral summer (Lee et al. 2019), and many individuals display site fidelity to Sydney Harbour, returning annually (Smoothey et al. 2019). Our results imply that levels of urbanisation are unlikely to substantially affect the predicted latitudinal shifts in bull shark presence in response to poleward extension of warmer waters due to climate change (Niella et al. 2020b).

Interactions between environmental drivers and the biological factors that shape the movements of marine predators are complex (Schlaff et al. 2014), ultimately requiring data on multiple species and sexes, habitat requirements, and variation in behaviour. In the face of rapid changes to marine environments, multi-species studies incorporating environmental drivers, at appropriate timeframes, are pertinent. Improvements in fine-scale data and subsequent analyses, e.g. those derived in this study using RSP (Niella et al. 2020a), enable us to quantify dynamic relationships between predators and prey, across multiple biological groups, thereby providing a detailed picture of dynamic intra- and inter-specific interactions across different habitats.

Supplementary Information The online version contains supplementary material available at https://doi.org/10.1007/s12237-021-01020-2.

Acknowledgements Financial support to YN through an International Macquarie University Research Training Program Scholarship is deeply acknowledged. We are extremely grateful to A. Murray, O. Masens, G. Barrett, M. Miller, D.E. van der Meulen, G. Cadiou, S. Brodie and C.A. Gray, and countless volunteers who assisted with the Sydney Harbour tagging programmes through NSW DPI, University of NSW, and Sydney Institute of Marine Science. The collection of tagging data used in this project was obtained through funding provided by numerous sources, including NSW Department of Primary Industries (DPI), NSW Recreational Fishing Saltwater Trust, Australian Research Council, Sydney Institute of Marine Science, and all data were available via the Integrated Marine Observing System (IMOS) Animal Tracking Facility web database. Tagging was performed under NSW DPI Animal Care and Ethics Committee permits 07/08 and 09/11, and NSW DPI Research Permit Section 37 (PO1/0059A-2.0).

Author Contribution YN, VMP, AFS, and RH conceived the ideas and designed the methodology; AFS and MDT oversaw data collection; YN analysed the data and led the writing of the manuscript. All authors contributed critically to the drafts and gave final approval for publication.

Data Availability Data were sourced from Australia's Integrated Marine Observing System (IMOS) - IMOS is enabled by the National Collaborative Research Infrastructure Strategy (NCRIS). It is operated by a consortium of institutions as an unincorporated joint venture, with the University of Tasmania as lead agent.

Open Access This article is licensed under a Creative Commons Attribution 4.0 International License, which permits use, sharing, adaptation, distribution and reproduction in any medium or format, as long as you give appropriate credit to the original author(s) and the source, provide a link to the Creative Commons licence, and indicate if changes were made. The images or other third party material in this article are included in the article's Creative Commons licence, unless indicated otherwise in a credit line to the material. If material is not included in the article's Creative Commons licence and your intended use is not permitted by statutory regulation or exceeds the permitted use, you will need to obtain permission directly from the copyright holder. To view a copy of this licence, visit http://creativecommons.org/licenses/by/4.0/.

\section{References}

Afonso A.S., H.A. Andrade and F.H.V. Hazin. 2014. Structure and dynamics of the shark assemblage off Recife, Northeastern Brazil. PLOS ONE 9:e102369.

Austin, D., W.D. Bowen, and J.I. McMillan. 2004. Intraspecific variation in movement patterns: Modelling individual behaviour in a large marine predator. Oikos 105: 15-30.

Austin, R.H., B.F. Phillips, and D.J. Webb. 1976. A method for calculating moonlight illuminance at the earth's surface. The Journal of Applied Ecology 13: 741.

Bansemer, C.S., and M.B. Bennett. 2011. Sex- and maturity-based differences in movement and migration patterns of grey nurse shark, 
Carcharias taurus, along the eastern coast of Australia. Marine and Freshwater Research 62: 596.

Barnett A., K.G. Abrantes, J.D. Stevens, B.D. Bruce and J.M. Semmens. 2010. Fine-scale movements of the broadnose sevengill shark and its main prey, the gummy shark. PLOS ONE 5:e15464-undefined.

Block, B.A., I.D. Jonsen, S.J. Jorgensen, A.J. Winship, S.A. Shaffer, S.J. Bograd, E.L. Hazen, D.G. Foley, G.A. Breed, A.L. Harrison, J.E. Ganong, A. Swithenbank, M. Castleton, H. Dewar, B.R. Mate, G.L. Shillinger, K.M. Schaefer, S.R. Benson, M.J. Weise, R.W. Henry, and D.P. Costa. 2011. Tracking apex marine predator movements in a dynamic ocean. Nature 475: 86-90.

Cherry, M.J., and B.T. Barton. 2017. Effects of wind on predator-prey interactions. Food Webs 13: 92-97.

Childs, A.R., P.D. Cowley, T.F. Næsje, A.J. Booth, W.M. Potts, E.B. Thorstad, and F. Økland. 2008. Do environmental factors influence the movement of estuarine fish? A case study using acoustic telemetry. Estuarine, Coastal and Shelf Science 78: 227-236.

Chin, A., M.R. Heupel, C.A. Simpfendorfer, and A.J. Tobin. 2016. Population organisation in reef sharks: New variations in coastal habitat use by mobile marine predators. Marine Ecology Progress Series 544: 197-211.

Cottrant, E., P. Matich, and M. Fisher. 2021. Boosted regression tree models predict the diets of juvenile bull sharks in a subtropical estuary. Marine Ecology Progress Series 659: 127-141.

Davies AB, C.J. Tambling, G.I.H. Kerley and G.P. Asner. 2016. Effects of vegetation structure on the location of lion kill sites in African thicket. PLoS ONE 11:e0149098.

DiGirolamo, A.L., S.H. Gruber, C. Pomory, and W.A. Bennett. 2012. Diel temperature patterns of juvenile lemon sharks Negaprion brevirostris, in a shallow-water nursery. Journal of Fish Biology 80: 1436-1448.

Duarte CM, L. Chapuis, S.P. Collin, D.P. Costa, R.P. Devassy, V.M. Eguiluz, C. Erbe, T.A.C. Gordon, B.S. Halpern, H.R. Harding, M.N. Havlik, M. Meekan, N.D. Merchant, J.L. Miksis-Olds, M. Parsons, M. Predragovic, A.N. Radford, C.A. Radford, S.D. Simpson, H. Slabbekoorn, E. Staaterman, I.C. van Opzeeland, J. Winderen, X. Zhang and F. Juanes. 2021. The soundscape of the Anthropocene ocean. Science 371.

Dwyer, R.G., H.A. Campbell, R.L. Cramp, C.L. Burke, M.A. MicheliCampbell, R.D. Pillans, B.J. Lyon, and C.E. Franklin. 2020. Niche partitioning between river shark species is driven by seasonal fluctuations in environmental salinity. Functional Ecology 34: 2170-2185.

Espinoza M, M.R. Heupel, A.J. Tobin and C.A. Simpfendorfer. 2016. Evidence of partial migration in a large coastal predator: opportunistic foraging and reproduction as key drivers. PLoS ONE 11:e0147608-undefined.

Espinoza, M., E.J.I. Lédée, A.F. Smoothey, M.R. Heupel, V.M. Peddemors, A.J. Tobin, and C.A. Simpfendorfer. 2021. Intra-specific variation in movement and habitat connectivity of a mobile predator revealed by acoustic telemetry and network analyses. Marine Biology 168: 1-15.

Espinoza, M., J. Matley, M.R. Heupel, A.J. Tobin, A.T. Fisk, and C.A. Simpfendorfer. 2019. Multi-tissue stable isotope analysis reveals resource partitioning and trophic relationships of large reefassociated predators. Marine Ecology Progress Series 615: 159-176.

Estupiñán-Montaño, C., J.F. Estupiñán-Ortiz, L.G. Cedeño-Figueroa, F. Galván-Magaña, and C.J. Polo-Silva. 2017. Diet of the bull shark, Carcharhinus leucas, and the tiger shark, Galeocerdo Cuvier, in the eastern Pacific Ocean. Turkish Journal of Zoology 41: 1111-1117.

Field, I.C., C.J.A. Bradshaw, H.R. Burton, M.D. Sumner, and M.A. Hindell. 2005. Resource partitioning through oceanic segregation of foraging juvenile southern elephant seals (Mirounga leonina). Oecologia 142: 127-135.

Flávio, H., and H. Baktoft. 2020. Actel: Standardised analysis of acoustic telemetry data from animals moving through receiver arrays. Methods in Ecology and Evolution 12: 196-203.
Gannon, R., N.L. Payne, I.M. Suthers, C.A. Gray, D.E. van der Meulen, and M.D. Taylor. 2015. Fine-scale movements, site fidelity and habitat use of an estuarine dependent sparid. Environmental Biology of Fishes 98: 1599-1608.

Gardiner, J.M., J. Atema, R.E. Hueter, and P.J. Motta. 2017. Modulation of shark prey capture kinematics in response to sensory deprivation. Zoology 120: 42-52.

Hammerschlag, N., R.A. Martin, and C. Fallows. 2006. Effects of environmental conditions on predator-prey interactions between white sharks (Carcharodon carcharias) and Cape fur seals (Arctocephalus pusillus pusillus) at Seal Island, South Africa. Environmental Biology of Fishes 76: 341-350.

Heupel, M.R., S.E.M. Munroe, E.J.I. Lédée, A. Chin, and C.A. Simpfendorfer. 2019. Interspecific interactions, movement patterns and habitat use in a diverse coastal shark assemblage. Marine Biology 166: 1-17.

Heupel, M.R., A.J. Tobin, M. Espinoza, C.A. Simpfendorfer, and E.J.I. Lédée. 2015. Contrasting movements and connectivity of reef-associated sharks using acoustic telemetry: Implications for management. Ecological Applications 25: 2101-2118.

Hoguane, A.M., E. da Cuamba, and L, Gammelsrød T,. 2012. Influence of rainfall on tropical coastal artisanal fisheries - a case study of Northern Mozambique. Revista De Gestão Costeira Integrada 12: 477-482.

Hueter, R.E., D.A. Mann, K.P. Maruska, J.A. Sisneros, and L.S. Demski. 2004. Sensory biology of elasmobranchs. In Biology of Sharks and Their Relatives, ed. J.C. Carrier, J.A. Musick, and M.R. Heithaus, 325-368. Boca Raton, FL, USA: CRC Press.

Hussey, N.E., S.T. Kessel, K. Aarestrup, S.J. Cooke, P.D. Cowley, A.T. Fisk, R.G. Harcourt, K.N. Holland, S.J. Iverson, J.F. Kocik, J.E.M. Flemming, and F.G. Whoriskey. 2015. Aquatic animal telemetry: A panoramic window into the underwater world. Science 348: 1255642.

Johnston, E.L., M. Mayer Pinto, and P.A. Hutchings. 2015. What we do and don't know about a highly diverse estuary. Marine and Freshwater Research 66: 1073-1087.

Jonsen, I.D., C.R. McMahon, T.A. Patterson, M. Auger-Méthé, R. Harcourt, M.A. Hindell, and S. Bestley. 2019. Movement responses to environment: Fast inference of variation among southern elephant seals with a mixed effects model. Ecology 100: 1-8.

Lazaridis E (2014) Lunar: Lunar phase \& distance, seasons and other environmental factors. http://statistics.lazaridis.eu. (accessed January 31, 2019)

Lea, J.S.E., B.M. Wetherbee, L.L. Sousa, C. Aming, N. Burnie, N.E. Humphries, N. Queiroz, G.M. Harvey, D.W. Sims, and M.S. Shivji. 2018. Ontogenetic partial migration is associated with environmental drivers and influences fisheries interactions in a marine predator. ICES Journal of Marine Science 75: 1383-1392.

Leduc AOHC, Nunes JACC, de Araújo CB, Quadros ALS, Barros F, Oliveira HHQ, Simões CRMA, Winandy GSM, Slabbekoorn H (2021) Land-based noise pollution impairs reef fish behavior: a case study with a Brazilian carnival. Biological Conservation 253:108910.

Lee, K.A., A.F. Smoothey, R.G. Harcourt, M. Roughan, P.A. Butcher, and V.M. Peddemors. 2019. Environmental drivers of abundance and residency of a large migratory shark, Carcharhinus leucas, inshore of a dynamic western boundary current. Marine Ecology Progress Series 622: 121-137.

Martin, R.A., and N. Hammerschlag. 2012. Marine predator-prey contests: Ambush and speed versus vigilance and agility. Marine Biology Research 8: 90-94.

McCord, M.E., and S.J. Lamberth. 2009. Catching and tracking the world's largest Zambezi (bull) shark Carcharhinus leucas in the Breede Estuary, South Africa: The first 43 hours. African Journal of Marine Science 31: 107-111.

Meynecke, J.O., S.Y. Lee, N.C. Duke, and J. Warnken. 2006. Effect of rainfall as a component of climate change on estuarine fish production in Queensland, Australia. Estuarine, Coastal and Shelf Science 69: 491-504. 
Niella, Y., H. Flávio, A.F. Smoothey, K. Aarestrup, M.D. Taylor, V.M. Peddemors, and R. Harcourt. 2020a. Refined shortest paths (RSP): Incorporation of topography in space use estimation from node-based telemetry data. Methods in Ecology and Evolution 11: 1733-1742.

Niella Y, V. Raoult, T. Gaston, V.M. Peddemors, R. Harcourt and A.F Smoothey. 2021a. Overcoming multi-year impacts of maternal isotope signatures using multi-tracers and fast turnover tissues in juvenile sharks. Chemosphere 269:129393.

Niella, Y., A.F. Smoothey, V. Peddemors, and R. Harcourt. 2020 b. Predicting changes in distribution of a large coastal shark in the face of the strengthening East Australian Current. Marine Ecology Progress Series 642: 163-177.

Niella, Y., A. Wiefels, U. Almeida, S. Jaquemet, E. Lagabrielle, R. Harbourt, V. Peddemors, and D. Guyomard. 2021b. Dynamics of marine predators off an oceanic island and implications for management of a preventative shark fishing program. Marine Biology 168: 1-18.

Niella YV, A.S. Afonso and F.H.V. Hazin. 2017. Bioecology and movements of bull sharks, Carcharhinus leucas, caught in a long-term longline survey off northeastern Brazil. Neotropical Ichthyology 15:e170106-undefined.

Otway, N.M., and M.T. Ellis. 2011. Pop-up archival satellite tagging of Carcharias taurus: Movements and depth/temperature-related use of south-eastern Australian waters. Marine and Freshwater Research 62: 607.

Papastamatiou, Y.P., C.G. Meyer, F. Carvalho, J.J. Dale, M.R. Hutchinson, and K.N. Holland. 2013. Telemetry and random-walk models reveal complex patterns of partial migration in a large marine predator. Ecology 94: 2595-2606.

Payne NL, D.E. van der Meulen, R. Gannon, J.M. Semmens, I.M. Suthers, C.A. Gray and M.D. Taylor. 2013. Rain reverses diel activity rhythms in an estuarine teleost. Proceedings of the Royal Society B: Biological Sciences 280.

Payne, N.L., D.E. van der Meulen, I.M. Suthers, C.A. Gray, and M.D. Taylor. 2014. Foraging intensity of wild mulloway Argyrosomus japonicus decreases with increasing anthropogenic disturbance. Marine Biology 162: 539-546.

Payne, N.L., C.G. Meyer, J.A. Smith, J.D.R. Houghton, A. Barnett, B.J. Holmes, I. Nakamura, Y.P. Papastamatiou, M.A. Royer, D.M. Coffey, J.M. Anderson, M.R. Hutchinson, K. Sato, and L.G. Halsey. 2018. Combining abundance and performance data reveals how temperature regulates coastal occurrences and activity of a roaming apex predator. Global Change Biology 24: 1884-1893.

Phillips NM, F. Devloo-Delva, C. McCall and T.S. DalyEngel. 2021. Reviewing the genetic evidence for sex-biased dispersal in elasmobranchs. Reviews in Fish Biology and Fisheries.

Pillans, R.D., J.P. Good, W.G. Anderson, N. Hazon, and C.E. Franklin. 2008. Rectal gland morphology of freshwater and seawater acclimated bull sharks Carcharhinus leucas. Journal of Fish Biology 72: 1559-1571.

Riverón, S., V. Raoult, A.M.M. Baylis, K.A. Jones, D.J. Slip, and R.G. Harcourt. 2021. Pelagic and benthic ecosystems drive differences in population and individual specializations in marine predators. Oecologia 196: 891-904.

Robins, J.B., I.A. Halliday, J. Staunton-Smith, D.G. Mayer, and M.J. Sellin. 2005. Freshwater-flow requirements of estuarine fisheries in tropical Australia: A review of the state of knowledge and application of a suggested approach. Marine and Freshwater Research 56: $343-360$

Roy, P.S., R.J. Williams, A.R. Jones, I. Yassini, P.J. Gibbs, B. Coates, R.J. West, P.R. Scanes, J.P. Hudson, and S. Nichol. 2001. Structure and function of south-east Australian estuaries. Estuarine, Coastal and Shelf Science 53: 351-384.

Schlaff, A.M., M.R. Heupel, and C.A. Simpfendorfer. 2014. Influence of environmental factors on shark and ray movement, behaviour and habitat use: A review. Reviews in Fish Biology and Fisheries 24: 1089-1103.
Schlaff AM, M.R. Heupel, V. Udyawer and C.A. Simpfendorfer. 2020. Sex-based differences in movement and space use of the blacktip reef shark, Carcharhinus melanopterus. PLOS ONE 15:e0231142.

Sims, D.W., M.J. Witt, A.J. Richardson, E.J. Southall, and J.D. Metcalfe. 2006. Encounter success of free-ranging marine predator movements across a dynamic prey landscape. Proceedings of the Royal Society B: Biological Sciences 273: 1195-1201.

Smoothey, A.F., C.A. Gray, S.J. Kennelly, O.J. Masens, V.M. Peddemors, and W.A. Robinson. 2016. Patterns of occurrence of sharks in Sydney Harbour, a large urbanised estuary. PLOS ONE 11: $1-16$.

Smoothey, A.F., K.A. Lee, and V.M. Peddemors. 2019. Long-term patterns of abundance, residency and movements of bull sharks (Carcharhinus leucas) in Sydney Harbour, Australia. Scientific Reports 9: 1-16.

Speed, C.W., I.C. Field, M.G. Meekan, and C.J.A. Bradshaw. 2010. Complexities of coastal shark movements and their implications for management. Marine Ecology Progress Series 408: 275-293.

Strickland, B.A., J.A. Massie, N. Viadero, R. Santos, K.R. Gastrich, V. Paz, P. O'Donnell, A.M. Kroetz, D.T. Ho, J.S. Rehage, and M.R. Heithaus. 2020. Movements of juvenile bull sharks in response to a major hurricane within a tropical estuarine nursery area. Estuaries and Coasts 43: 1144-1157.

Taylor, M.D., A. Becker, and M.B. Lowry. 2018a. Investigating the functional role of an artificial reef within an estuarine seascape: A case study of yellowfin bream (Acanthopagrus australis). Estuaries and Coasts 41: 1782-1792.

Taylor, M.D., D.E. van der Meulen, S. Brodie, G. Cadiou, and N.A. Knott. 2018b. Applying acoustic telemetry to understand contaminant exposure and bioaccumulation patterns in mobile fishes. Science of the Total Environment 625: 344-354.

Taylor, M.D., D.E. van der Meulen, M.C. Ives, C.T. Walsh, I. Reinfelds, and v., Gray CA,. 2014. Shock, stress or signal? Implications of freshwater flows for a top-level estuarine predator. PLOS ONE 9: $1-10$.

Tillett, B.J., M.G. Meekan, and I.C. Field. 2014. Dietary overlap and partitioning among three sympatric carcharhinid sharks. Endangered Species Research 25: 283-293.

Trystram, C., K.M. Rogers, M. Soria, and S. Jaquemet. 2017. Feeding patterns of two sympatric shark predators in coastal ecosystems of an oceanic island. Canadian Journal of Fisheries and Aquatic Sciences 74: 216-227.

Udyawer, V., A. Chin, D.M. Knip, C.A. Simpfendorfer, and M.R. Heupel. 2013. Variable response of coastal sharks to severe tropical storms: Environmental cues and changes in space use. Marine Ecology Progress Series 480: 171-183.

de Vincenzi, G., P. Micarelli, S. Viola, G. Buffa, V. Sciacca, V. Maccarrone, V. Corrias, F.R. Reinero, C. Giacoma, and F. Filiciotto. 2021. Biological sound vs. Anthropogenic noise: Assessment of behavioural changes in Scyliorhinus canicula exposed to boats noise. Animals 11: 1-15.

Waite, J.N., S.J. Trumble, V.N. Burkanov, and R.D. Andrews. 2012. Resource partitioning by sympatric Steller sea lions and northern fur seals as revealed by biochemical dietary analyses and satellite telemetry. Journal of Experimental Marine Biology and Ecology 416-417: 41-54.

Walsh, C.T., I. Reinfelds, and v., Ives MC, Gray CA, West RJ, van der Meulen DE,. 2013. Environmental influences on the spatial ecology and spawning behaviour of an estuarine-resident fish, Macquaria colonorum. Estuarine, Coastal and Shelf Science 118: 60-71.

Ward, A.J.W., M.M. Webster, and P.J.B. Hart. 2006. Intraspecific food competition in fishes. Fish and Fisheries 7: 231-261.

Werry, J.M., S.Y. Lee, N.M. Otway, Y. Hu, and W. Sumpton. 2011. A multi-faceted approach for quantifying the estuarine-nearshore transition in the life cycle of the bull shark, Carcharhinus leucas. Marine and Freshwater Research 62: 1421-1431. 
Werry J.M., W. Sumpton, N.M. Otway, S.Y. Lee, J.A. Haig and D.G. Mayer. 2018. Rainfall and sea surface temperature: key drivers for occurrence of bull shark, Carcharhinus leucas, in beach areas. Global Ecology and Conservation 15:e0430.

Widmer, W.M., and A.J. Underwood. 2004. Factors affecting traffic and anchoring patterns of recreational boats in Sydney Harbour, Australia. Landscape and Urban Planning 66: 173-183.
Wintner, S.P., and S.E. Kerwath. 2018. Cold fins, murky waters and the moon: What affects shark catches in the bather-protection program of KwaZulu-Natal, South Africa? Marine and Freshwater Research 69: 167-177.

Wood S.N. 2017. Generalized Additive Models: An Introduction with R, 2nd ed. Chapman and Hall/CRC. 